\title{
Research on Virtual Reality Technology in Traditional Architecture Protection
}

\author{
Jian Xiao ${ }^{1, a^{*}}$, SiYu Guo ${ }^{1, b}$, TengFei Zhou ${ }^{1, c}$ \\ ${ }^{1}$ Dalian Polytechnic University, DaLian, LiaoNing, China \\ a*497524298@qq.com \\ b1311693922@qq.com \\ czz1787859090@163.com
}

\begin{abstract}
Intangible cultural heritage records the history and changes of Chinese traditional culture. It is a living fossil of regional economy, culture and politics. It is an indispensable part of the treasure house of Chinese cultural information. Using big data to build a digital platform for intangible cultural heritage collection, storage and sharing of relevant data resources are the prerequisites for the involvement of virtualreality technology in intangible cultural heritage management.
\end{abstract}

Keywords: Virtual reality, technology, traditional architecture, protection

\section{INTRODUCTION}

With the high-speed development of Internet technology in recent years, the key technologies of virtual reality are gradually mature, and virtual reality technology based on various type terminal equipment has also achieved major breakthroughs, and their higher exquisite, stronger interaction, more convenient operation. It is common to use in various industries. Its research results are also widely used in the real environmental costs of medical training, experimental teaching, military drills, and engineering training. ${ }^{[1]}$

Virtual reality technology, also known as spiritual technology, a new digital presentation technology developed in the twentieth century, which combines computer, electronic information, simulation model. The basic working principle is the establishment of virtual simulation scenes to the user's immersive deep immersion, in terms of visual, auditory or even tactile, smell, etc. using a virtual digital environment that is highly similar to the real environment in terms of smell, 3D glasses, helmets and other equipment are used to interact with the digital objects in the virtual simulation environment.

The climate conditions and ethnic customs in Liaoning have long the unique features of Manchu residential buildings, but with the passage of time and the changes of human living areas, many Manchu traditional buildings have been greatly destroyed to a great extent. The constant erosion of natural forces makes the architecture lose its once full colour, and the traces of modern life make the traditional form of architecture more and more blurred. In response to the crisis facing traditional buildings, the state has developed relevant laws and regulations in the protection system, such as the "Law of the People's Republic of China on the Protection of Cultural Relics", "The Regulation on the Protection of Famous Cultural Cities, Towns and Villages" and other policy issuance, all express the government decisions and efforts to effectively protect traditional historical residential buildings.

\section{TRADITIONAL ARCHITECTURE}

Through the preliminary investigation and planning of the protected building community, the model data acquisition of model data is required. ${ }^{[2]}$ In the choice of target objects, the basic principles are highlighted in the profile characteristics, the preservation state is good, targeted inheritance protection and innovative application research value. Based on the full investigation of the appearance, structure, cultural and historical background of the target building, the scanning method and scanning path in line with the project are planned. For the nightclub without the appearance and shape of the target building, appropriate equipment is selected for three-dimensional scanning. 
Fixed point positioning during building scanning can minimize the impact of moving objects on data acquisition accuracy and avoid model data errors. After successful data acquisition, the model is modified by three-dimensional software and finally stores the model.

With the rapid development of network informatization in recent years, all countries in the world have begun to conduct record protection of intangible cultural heritage in digital concepts. UNESCO has launched the "World Memory Project", which makes the global cultural heritage systematically recorded and presented in digital form for the first time. Due to technical constraints, although China is relatively late in the digital protection of intangible cultural heritage, the post-development is relatively rapid, especially the ministry of culture listed the "China Intangible Cultural Heritage digital protection project" as a national planning project in 2010. The original model acquisition method often adopts mold turning or sculpture, but since the target itself has certain destructiveness, it will lead to a decline in the real degree of the model. In order to maintain a high degree of consistency with real target buildings, the method of establishing a three-dimensional scanning digital model is generally employed. At the same time, the introduction of the intangible cultural heritage law of the People's Republic of China also provides legal support for the digital protection of intangible cultural heritage. ${ }^{[3]}$

\section{CHARACTERISTICS OF ARCHITECTURE}

Since the Ming Dynasty, Manchu people have been moving southward. With the change of natural environment, their lifestyle has gradually changed from traditional hunting to farming culture with the characteristics of inland culture. At the same time, their building materials, structure and technology have also changed greatly. The original adobe material has become the building material with brick and tile as the main body, and the standardized wooden building construction has also begun to be used on a large scale. At the same time, the traditional "pocket room" began to evolve into a form of axial symmetry, with the main room as the center and the east-west wing rooms twice, "Sanheyuan" and "Siheyuan", which also marked that the moral and ethical system and the key of the hierarchy of Han culture gradually affected the Manchu culture.

For the "traditional national architectural style", we should ensure that the inheritance of traditional architectural style is accurate, and cannot make subjective assumptions because of seeking innovation and change. The Manchu architecture of "traditional national architectural style" is fully reflected in the national cultural connotation, national artistic characteristics, regional aesthetics and so on. Traditional national architecture exists as art treasures, and has high value in formal beauty and use function.

The architectural form of Manchu inhabited areas is based on the local natural climate and environmental conditions, fully absorbs the national history, culture, customs, beliefs and other factors, and creates an architectural form with the essence of traditional national residential culture after the verification of practical life. This is an active form, which can fully coordinate and unify the architectural state with the natural environment from the perspective of respecting nature, and fully meet the aesthetic consciousness and ethical spirit of different ethnic groups. In the long-term development process, the architectural form of Manchu nationality has gradually changed by absorbing the architectural art forms of other nationalities. It is interactive and integrated in architectural structure, pattern style and color. At the same time, Manchu architecture retains the essence of typical traditional architectural culture unique to its own nation and region to the greatest extent. Thus, an artistic expression form with strong Manchu architectural structure and decorative style has been formed, which can fully meet the actual needs of national life and have the use value of national architectural cultural heritage.

In the means of reflecting its "national traditional style", Manchu traditional architecture takes its own Manchu traditional culture as the basic element, comprehensively understands and analyzes the basic forms of Manchu traditional culture and architecture, and deeply excavates and analyzes the unique cultural characteristics and cultural elements of this nation. The analysis and treatment of architectural elements are also gradually developing in the direction of innovation. In this way, a lot of Manchu elements and Manchu culture are integrated into the architectural field, which creates a better environmental atmosphere for the deep display of architectural Manchu atmosphere.

According to the survey, the protection of world intangible cultural heritage has been dominated by traditional methods for a long time. It usually uses paper documents, photos and other methods to preserve relevant resources. This form often causes material damage and irreparable loss over time, natural and man-made disasters and other situations. As the modern technology in most areas where many intangible cultural heritages are located is generally relatively backward, and their protection concepts and means are relatively old, the development of intangible cultural heritage protection is relatively slow.

The Manchu traditional architectural profile is unlike the southern architecture with extremely distinct local characteristics, its roof still maintains a traditional Chinese architectural double roof form - hard mountain top. With the continuous impact on the architectural 
form of the Han nationality, the simplified single eave Xieshan top with "eight-character" has become an important feature of the traditional architecture of the Manchu nationality ${ }^{[4]}$.In the traditional concept of building, the top of the mountain is a roof form of the top of the Hall. In the specific design process, the main ridge, four vertical ridges and four berm ridges are the core elements, basically showing the basic style of hanging the mountain top.

The digital research of Manchu intangible cultural heritage provides an extremely abundant materials for national cultural creative design. Digital information has outstanding advantages such as accuracy, timeliness, dynamics and interactivity that users are very convenient to store, retrieve and share digital information, which has the characteristics of high-speed communication and real-time sharing. Therefore, in the inheritance and innovation design of Manchu traditional culture, the introduction of digital technology has very high actual value.

\section{APPLICATION PATH}

A presence and presentation of "National Traditional People's Style", which exhibited colour and attributes of the full Mann culture among the entire building. In the design process, we have a comprehensive understanding of the meaning of colour and its application, so that the design activity is more accommodated in the manner. For example, in the ideological cognition of the Manchu people, red is a very traditional cultural colour, symbolizing the king, while yellow represents the most noble status. Therefore, red walls and yellow tiles are mostly used in Manchu palace buildings. According to Shamanism, which is the most popular in Manchu areas, white is the purest colour, so a large area of gray white walls are also painted in many architectural communities. In every part of the building, we can see the colour of highlighting cultural properties, and each colour is actually a traditional culture penetration and story. Through the analysis, during different development periods, the Manchu architectural features are different, but under the deep influence of inherent traditional culture, the model design of architecture, the colour planning of construction, etc. can be very clear. Reflecting the awareness of the whole nation to respect, for the expression of family philosophy,

In actual life, in order to obtain a better environment, people are also actively committed to the transformation and innovation of these traditional buildings. This can also lay the foundation for the demonstration of architectural vitality. For those historical buildings that have long construction time, they shall be divided according to different years and periods, and they shall not be demolished or changed at will; for those buildings that are relatively old but not very strong in practical cultural significance, they can be repaired according to the relevant principles. In the process of development and utilization, the original morphology and appearance of the entire building should be maintained, and the modernization process is used to repair. [5]

The establishment of standards plays an important role in the digital construction of virtual simulation of intangible cultural heritage. Because in the process of building various digital information platforms, if there are non-uniform operation standards and non-standard data collection, it will seriously affect the accuracy of digital information of intangible cultural heritage, and cannot fundamentally establish a database consistent with the actual situation of intangible cultural heritage, and unable to truly give full play to the practical value of digital technology. It will even lead to the failure of the digital protection of intangible cultural heritage.

Establishing a digital image information platform for Manchu living space, and conducting field investigation in Manchu township and other minority inhabited areas in southern Liaoning are very necessary. Due to the speed of urbanization, many Manchu traditional buildings have been recorded in large demolitions because they do not meet the modern urban planning and life needs. The existing reserved Manchu folk houses have been recorded on the spot and photographed. At the same time, the spatial information technology, big data technology, streaming media technology and cloud computing technology have been used for realizing the real-time positioning, resource display and data analysis of the traditional protective space of Manchu in Liaoning. And establishing the digital image information platform of Manchu living space will greatly promote the inheritance of Manchu traditional living space in southern Liaoning. The creative transformation and information dissemination and utilization of innovative achievements, in cultural heritage protection, public cultural services, cultural and creative industries regional cultural exchanges and many other aspects play an important role. Taking rural towns in Manchu inhabited areas as the research carrier, this paper explores the theory, method and practice of the protection and development of traditional ethnic architectural villages. Using comprehensive means such as image information collection, multimedia technology and computer graphics, the images of towns with Manchu characteristics are digitally protected. Finally, with the help of the internet, they are displayed on digital terminals such as computers and smart phones, so that people can actively perceive the local characteristic national cultural resources through the interactive interface and understand the cultural information contained in various types of buildings, more convenient and faster to know the full of mansions. 


\section{CONCLUSION}

Through collecting image data of intangible cultural heritage, we can formulate image acquisition standards according to the types of cultural heritage to ensure the effectiveness and rationality of image data acquisition. While storing cultural heritage digital data, resource storage standards can be formulated, such as storage format standards for different data types, data volume standards. Additionally, building a standardized retrieval system of intangible cultural heritage digital resources, due to China is rich in intangible cultural heritage resources. In order to improve the utilization efficiency of digital cultural heritage, we must establish a perfect retrieval system and strengthen the network connection between display data, so as to give full play to the value of digital resource platform. For example, in the construction of the intangible cultural heritage digital resource platform, a diversified retrieval method can be established, such as text retrieval, semantic retrieval, and content retrieval, but text retrieval features need to be marked, not applicable to large quantity data retrieve. In contrast, content retrieval technology is more intelligent, which combines multimedia identification and pattern recognition technology, which can be more accurately locked, and it is very suitable for retrieval of non-material cultural heritage resources.

\section{ACKNOWLEDGMENTS}

National Social Science Foundation of China Art Program, 21BG127, 2021.

\section{REFERENCES}

[1] Jian Xiao, The application of Manchu traditional cultural elements in architectural design, Art Education Research, 2016(5):170-170. DOI:10.3969/j.issn.1674-9286.2016.05.122.

[2] Xiaoqing Duan, The application of virtual reality to the protection of intangible cultural heritages, Studies in culture \& art, 2020,13(1):19-23. DOI:10.3969/j.issn.1674-3180.2020.01.004.

[3] Junbo Dai, Construction of digital museum of Manchu intangible cultural heritage based onvirtual reality technology, Journal of Tonghua normal university, 2021(2015-1): 48-52. DOI:10.13877/j.cnki.cn22-1284.2015.01.009

[4] Qibo Liu, JingfengTian, Probe into humanist environment protection of architecture in urban and rural under the concept of green architecture, Optimization of capital construction 2005, 26(5): 91-94.

[5] Weitao Zhao, Tianming Yue, Yuxia Gao et al, Research on Manchu residential culture and rural landscape planning, Journal of Shenyang
AriculturalUniversity,2008,10(6):733-737, DOI:10.3969/j.issn.1008-9713.2008.06.026. 